\title{
sciendo
}

\section{THE EFFECT OF DIET WITH FERMENTED SOYBEAN MEAL ON BLOOD METABOLITES AND REDOX STATUS OF CHICKENS}

\author{
Iwona Sembratowicz, Robert Chachaj, Magdalena Krauze, Katarzyna Ognik \\ Department of Biochemistry and Toxicology, Faculty of Animal Sciences and Bioeconomy, \\ University of Life Sciences in Lublin, Akademicka 13, 20-950 Lublin, Poland \\ •Corresponding author: kasiaognik@poczta.fm
}

\begin{abstract}
The aim of the study was to determine whether replacing soybean meal with $3 \%$ or $6 \%$ fermented soybean meal would positively affect blood metabolites and redox status of broiler chickens. The experiment was carried out on 600 broiler chickens assigned to three experimental groups of 200 chickens each (10 replications of 20 individuals each). In the control group, soybean meal (SBM) was the main source of dietary protein, whereas the remaining groups were fed diets in which soybean meal was partially replaced with $3 \%$ or $6 \%$ fermented soybean meal (FSBM-3\%, FSBM$6 \%$ ). The fermentation of the SBM contributed to an increase of Lactobacillus, content of crude protein, methionine and lysine, and especially over a 30-fold increase in the concentration of lactic acid. The inclusion of $3 \%$ or $6 \%$ share of FSBM in the diet of chickens contributed to an increase in total antioxidant potential (FRAP) and plasma total glutathione content. In blood of chickens receiving FSBM an increase of total protein and $\mathrm{HDL}$ cholesterol content, aspartate aminotransferase activity and a decrease in urea content were noted. In addition to the positive effect on protein and lipid metabolism as well as antioxidant defence, the diet with a $6 \%$ share of FSBM improved body weight gain of chickens. In conclusion, it can be suggested that introducing $6 \%$ share of FSBM in place of FSM is more justified.
\end{abstract}

Key words: chicken, fermented soybean meal, antioxidant, biochemical parameters

Fermented protein products, including fermented soybean meal (FSBM), are becoming increasingly popular in animal production (Sugiharto and Ranjitkar, 2019). Fermentation is an effective process that improves the nutritional value of feed and its microbiological characteristics. Owing to the activity of microbial proteases, soybean proteins are degraded into easily digestible low-molecular-weight peptides and amino acids (Frias et al., 2008; Hong et al., 2004). Fermentation causes degradation of many anti-nutritional factors (ANFs), such as tannins, galacto-oligosaccharides, trypsin inhibitors, lectins, non-starch polysaccharides (NSPs), and allergen proteins (glycinin, B-conglycinin), which limit the use of soybean meal in the diet of mo- 
nogastric animals, especially young animals (Mukherjee et al., 2016; Soumeh et al., 2019; Drażbo et al., 2019). A great benefit of fermentation is that it enriches feed with probiotic microorganisms (e.g. Lactobacillus sp., Bacillus sp., or Saccharomyces cerevisiae) (Ashayerizadeh et al., 2017; Soumeh et al., 2019). The substances they secrete, such as organic acids or bacteriocins, reduce the risk of inflammation and diarrhoea by creating unfavourable conditions for the development of intestinal pathogens (Engberg et al., 2009; Jazi et al., 2019). Numerous studies have shown measurable benefits of introducing fermented soybean meal into the diet of poultry: better growth performance, modulation of the immune system, and improved intestinal histology and microbiome (Chachaj et al., 2019 a, b; Feng et al., 2007 a, b; Jazi et al., 2018; Kim et al., 2016; Mathivanan et al., 2006). Some reports (Chachaj et al., 2019 b, Jazi et al., 2018) have shown that diet with FSBM affects lipids blood parameters in poultry (an increase in HDL-cholesterol, a decrease in total cholesterol, triacylglycerols and LDL-cholesterol). The studies on turkeys and chickens have revealed that the feeding with fermented soybean meal has also influenced protein metabolism as evidenced by an increase in total protein in plasma (Chachaj et al., et al., 2019 b) and a decrease in blood urea nitrogen (Feng et al., 2007 a). Moreover, there are reports indicating that dietary inclusion of fermented soybean meal may enhance natural antioxidant mechanisms in turkeys (Chachaj et al., 2019 b) as well as in other animals (Choi et al., 2016; Luo et al., 2018).

It is worth noting that soybean is a rich source of isoflavones, which possess strong antioxidant activity, however, these are present in the form of poorly absorbable glycosides (Makowska-Wąś and Janeczko, 2004). Fermentation not only eliminates many of the soybean ANFs but also contributes to the breakdown of glycosides with the release of active aglycones, characterized by high bioavailability and by strong antioxidant and anti-inflammatory properties (Champagne et al., 2010). Fermentation of soybean also increases the amount of other antioxidants, such as small peptides, and micronutrients ( $\mathrm{Fe}$ and $\mathrm{Zn}$ ), which are necessary for the activity of antioxidant enzymes (Hirabayashi et al., 1998, Chatterjee et al., 2018). Therefore, there are indications that replacing SBM with FSBM in chicken feeds may reduce the severity of oxidative and inflammatory reactions by enhancing antioxidant defence mechanisms. The study on turkeys receiving FSBM as a partial replacement of FSM (at the level of 7\%) demonstrated positive influence of such a diet on antioxidant system (Chachaj et al., 2019 b). However, 9-10\% share of FSBM in the diet led to adverse effects in form of intensification of oxidative and inflammatory reactions. Therefore, the selection of appropriate share of FSBM in poultry diet is very important. Considering the possibility of replacing FSM by FSBM, it should be taken into account that fermentation of protein-rich soybean leads to formation of biogenic amines (histamine, putrescine, tyramine) which may have negative impact on metabolism and poultry health (Mah et al., 2019). In addition, fermented feed may contain less amounts of some phytochemicals: phytosterols, tocopherols (Hubert et al., 2008) as compared to raw material. Changes in different compounds content in the seeds, during fermentation depends on this process condition and starter culture employed. 
The available literature lacks information about the effect of the use of fermented soybean meal on antioxidant system of chickens and data about the impact of such a diet on blood biochemical indicators are insufficient. We hypothesise that due to reductions of soybean allergens and presence of active ingredients (antioxidants, probiotic microflora) the diet with FSBM may positively influence metabolism and antioxidant system of chickens.

Therefore, the aim of the study was to determine whether replacing raw soybean meal with $3 \%$ or $6 \%$ fermented soybean meal would positively affect blood metabolites and redox status parameters in chickens.

\section{Material and methods}

\section{Fermented protein products}

Fermented soybean meal (FSBM) from European Protein (Bække, Denmark) was used in the study. Fermented soybean meal was prepared from soy by-products i.e. solvent-extracted soybean meal (SBM, containing $470 \mathrm{~g} / \mathrm{kg}$ crude protein (CP)) that were fermented and then dried, with added potatoes and selected lactic acid bacteria. The composition of the SBM and FSBM is presented in Table 1. The source of carbon for Lactobacillus bacteria cultivation consisted of potato starch, potatoes and wheat.

Table 1. Composition of soybean meal (SBM) and fermented soybean meal (FSBM)

\begin{tabular}{l|r|r}
\hline \multicolumn{1}{c}{ Ingredients (g/kg) } & SBM & FSBM \\
\hline Dry matter & 897.2 & 895.0 \\
Crude protein & 470.5 & 505.0 \\
Crude fat & 19.9 & 22.0 \\
Crude fibre & 35.8 & 34.0 \\
Crude ash & 64.5 & 64.0 \\
Non-starch polysaccharides (NSP) & 124.3 & 114.0 \\
Lactic acid & 1.9 & 74.0 \\
Lysine & 24.6 & 27.9 \\
Methionine & 5.8 & 6.9 \\
Threonine & 17.4 & 19.8 \\
Tryptophan & 6.2 & 6.4 \\
Lactobacillus log CFU/g & 4.2 & 6.9 \\
TI* & 2.9 & $<0.5$ \\
B-conglycinin & 58.9 & $<2$ \\
Raffinose & 45.0 & $<5$ \\
\hline
\end{tabular}

*TI - trypsin inhibitors. 


\section{Animals and diets}

The material for the study consisted of one-day-old male Ross 308 chickens raised to the age of 40 days. The experimental procedure was approved by the Second Local Ethics Committee for Experiments with Animals in Lublin (approval no. 30/2016). The chickens were raised in pens on litter until the age of 40 days in a building with a controlled environment, and they had free access to feed and water. Zoohygienic conditions were as follows: humidity $-65-66 \%$, temperature - about $20^{\circ} \mathrm{C}$, lighting - 20 lux (1-21 days, then gradually reduced to 10 lux). As litter material the straw was chopped (10 cm depth, 18\% humidity). In the chicken house forced-air supply ventilation was used. The experiment was carried out on 600 chickens assigned to three experimental groups of 200 birds each (10 replications of 20 individuals each). During each of three feeding phases, the birds were fed isonitrogenous and isocaloric diets in pellet form ad libitum. In the control group, soybean meal was the main source of dietary protein, whereas the remaining groups were fed diets in which soybean meal was partially replaced with $3 \%$ or $6 \%$ fermented soybean meal (FSBM-3\%, FSBM-6\%). The diets were prepared by Trouw Nutrition (Poland). The nutritional value of the diets was in accordance with the nutrient requirements of chickens. Their composition was established in accordance with Smulikowska and Rutkowski (2005). Table 2 presents the composition of the control and experimental diets prepared in each feeding period.

\section{Growth trial and sample collection}

At the end of each period, the body weights, feed intake, and mortality rates of the chickens were recorded, with each pen of 20 birds considered an experimental unit. Body weight gain (BWG), daily feed intake (DFI), and feed conversion ratio (FCR) were calculated for each group. At the end of the experiment, at 40 days of age, nine birds representing the average BW per treatment were selected, tagged and fasted for $8 \mathrm{~h}$. Blood samples were collected from the wing vein intravitally, and birds were sacrificed by cervical dislocation.

\section{Laboratory analysis}

The plasma content of total cholesterol (TC), high-density lipoprotein (HDL) cholesterol, triacylglycerols (TG), uric acid (UA), urea (UREA), total protein (TP), glucose (GLU), creatinine (CREAT) and bilirubin (BIL), as well as the activity of alanine aminotransferase (ALT), aspartate aminotransferase (AST), creatine kinase (CK), and gamma-glutamyl transferase (GGT), were measured using an automatic biochemical analyser (Plasma Diagnostic Instruments Horiba, Kyoto, Japan). Mineral (Fe, $\mathrm{Cu}$, and $\mathrm{Zn}$ ) content in the blood samples was determined by FAAS. Markers of oxidative stress determined in the blood included lipid oxidation indicators, i.e. the concentration of lipid hydroperoxides ( $\mathrm{LOOH}$ ) and malondialdehyde (MDA), using kits produced by Blue Gene Biotech (Shanghai, China) and Cell Biolabs, Inc. (San Diego, USA), respectively. Total glutathione (GSH+GSSG) was determined in the blood using a Total Glutathione Assay (Cell Biolabs, Inc., San Diego, USA). Superoxide dismutase (SOD) and catalase (CAT) activity and total antioxidant potential (FRAP) were determined according to methods described by Ognik and Wertelecki (2012). 


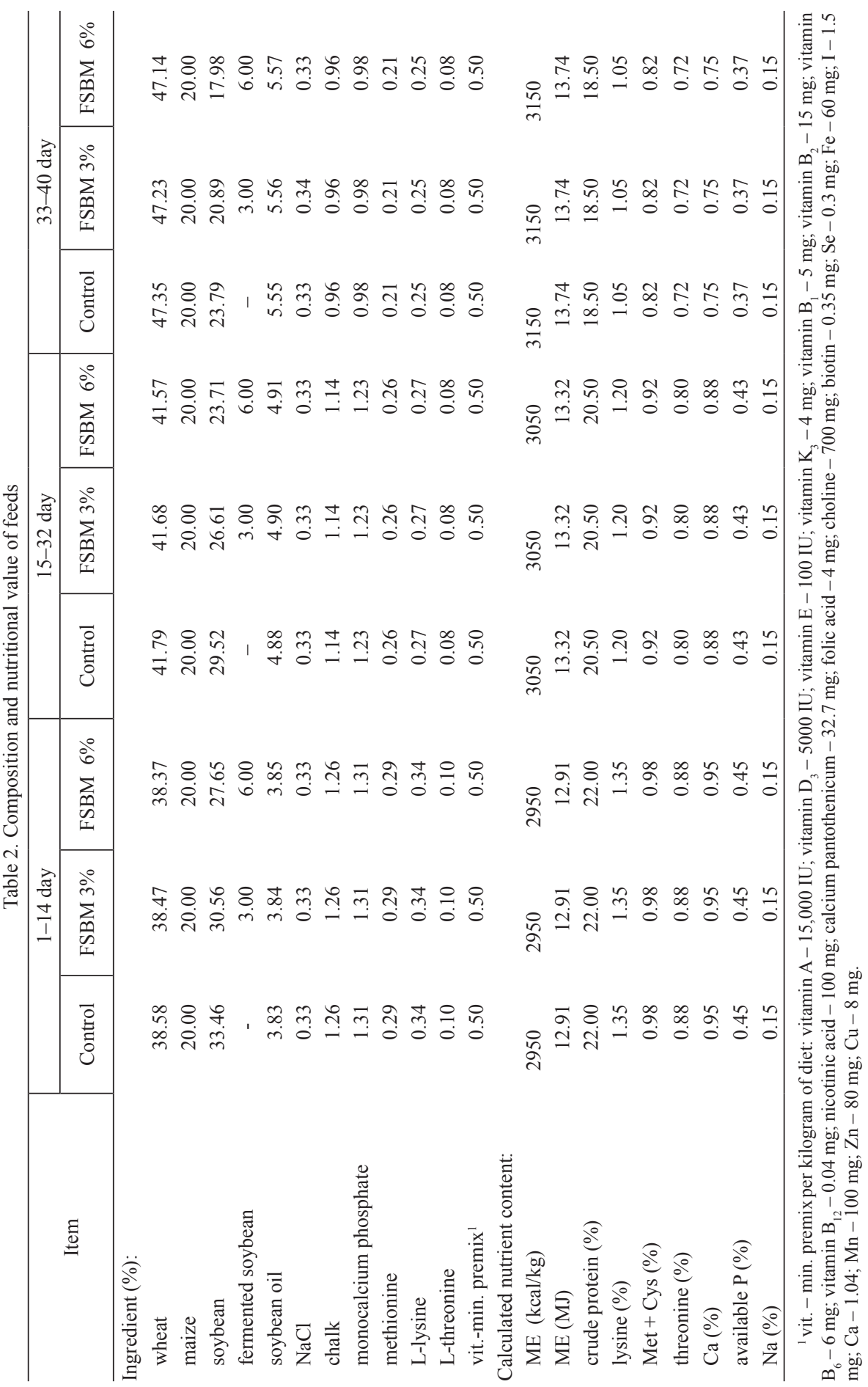




\section{Statistical analysis}

Data were processed by one-way analysis of variance (ANOVA) and the results were presented as mean values with pooled standard error (SEM) (StatSoft Polska, Kraków, Poland, 2009). Differences among means were compared using Duncan's multiple-range test. Treatment effects were considered to be significant at $\mathrm{P} \leq 0.05$.

\section{Results}

The fermentation of SBM contributed to an increase of Lactobacillus, content of $\mathrm{CP}$, methionine and lysine, and especially over a 30-fold increase in the concentration of lactic acid (Table 1). Analysing the effects of rearing of chickens receiving diet with FSBM, it was concluded that a $6 \%$ share caused an improvement in BWG $(\mathrm{P}=0.017)$, but it did not affect the remaining parameters (Table 3$)$. As shown in Table 4, the TP level in the plasma of chickens fed 3\% and 6\% FSBM increased $(\mathrm{P}=0.042)$ relative to the control group, while the content of urea and bilirubin decreased $(\mathrm{P}=0.039, \mathrm{P}=0.021)$. The plasma level of GLU, CREAT and TG in the chickens receiving FSBM did not change, but there were modifications in TC and its HDL fraction. The highest plasma TC content was noted in the birds receiving a 3\% share of FSBM, and the lowest in the group receiving 6\% FSBM $(\mathrm{P}=0.047)$. The inclusion of $3 \%$ and $6 \%$ FSBM in the diet caused an increase in HDL cholesterol $(\mathrm{P}=0.021)$, (Table 5). According to the data presenting the activity of selected enzymes in the chicken plasma, the diet containing FSBM (3\% and 6\%) only caused an increase in AST activity $(\mathrm{P}=0.044)$ (Table 6). Analysis of redox parameters showed that the diet with a share of $3 \%$ or $6 \%$ did not affect the activity of antioxidant enzymes SOD and CAT or the lipid peroxidation parameters $\mathrm{LOOH}$ and MDA. However, it caused an increase in FRAP and its component GSSG+GSH $(\mathrm{P}<0.001, \mathrm{P}=0.021$, respectively) (Table 7). Compared with the control group, the $3 \%$ and $6 \%$ FSBM resulted in an increase in $\mathrm{Zn}(\mathrm{P}=0.001)$ and $6 \% \mathrm{FSBM}$ resulted in an increase in $\mathrm{Cu}$ $(\mathrm{P}<0.001)$ content but decreased $\mathrm{Fe}(\mathrm{P}<0.001)$ level in the blood plasma of chicken (Table 8).

Table 3. Growth performance of chickens receiving diet containing fermented soybean meal (FSBM)

\begin{tabular}{l|l|c|c|c}
\hline \multicolumn{1}{c|}{ Treatment } & $\begin{array}{c}\text { Av. BWG } \\
(\mathrm{kg})\end{array}$ & $\begin{array}{c}\text { DFI } \\
(\mathrm{g} / \mathrm{bird} / \text { day })\end{array}$ & $\begin{array}{c}\text { FCR } \\
(\mathrm{kg} / \mathrm{kg})\end{array}$ & $\begin{array}{c}\text { Mortality } \\
(\%)\end{array}$ \\
\hline Control & $2.064 \mathrm{~b}$ & 0.086 & $1.682 \mathrm{ab}$ & 1.5 \\
FSBM $-3 \%$ & $2.087 \mathrm{ab}$ & 0.085 & $1.630 \mathrm{~b}$ & 2.0 \\
FSBM $-6 \%$ & $2.094 \mathrm{a}$ & 0.089 & $1.700 \mathrm{a}$ & 0.5 \\
SEM & 0.017 & 0.004 & 0.012 & NA \\
P-value & 0.039 & 0.347 & 0.041 & NA \\
\hline
\end{tabular}

$\mathrm{a}, \mathrm{b}$ - means with different letters within a row are significantly different at $\mathrm{P} \leq 0.05$; $\mathrm{SEM}$ - standard error of mean; BWG - body weight gain, DFI - daily feed intake; FCR - feed conversion ratio, NA - not analysed. 
Table 4. Parameters of protein metabolism in the blood plasma of the chickens receiving fermented soybean meal (FSBM)

\begin{tabular}{l|c|c|c|c|c}
\hline \multicolumn{1}{c|}{ Treatment } & $\begin{array}{c}\text { TP } \\
(\mathrm{g} / \mathrm{L})\end{array}$ & $\begin{array}{c}\text { ALB } \\
(\mathrm{g} / \mathrm{L})\end{array}$ & $\begin{array}{c}\text { UA } \\
(\mathrm{mmol} / \mathrm{L})\end{array}$ & $\begin{array}{c}\text { UREA } \\
(\mathrm{mmol} / \mathrm{L})\end{array}$ & $\begin{array}{c}\text { BIL } \\
(\mu \mathrm{mol} / \mathrm{L})\end{array}$ \\
\hline Control & $28.29 \mathrm{~b}$ & 0.010 & 141.2 & $1.366 \mathrm{a}$ & $18.06 \mathrm{a}$ \\
FSBM $-3 \%$ & $32.73 \mathrm{a}$ & 0.011 & 146.6 & $1.010 \mathrm{~b}$ & $12.64 \mathrm{~b}$ \\
FSBM $-6 \%$ & $31.35 \mathrm{a}$ & 0.010 & 142.6 & $1.090 \mathrm{~b}$ & $9.030 \mathrm{c}$ \\
SEM & 0.036 & 0.001 & 0.024 & 0.232 & 0.087 \\
P-value & 0.042 & 1.236 & 0.242 & 0.039 & 0.021 \\
\hline
\end{tabular}

$\mathrm{a}, \mathrm{b}-$ means with different letters within a row are significantly different at $\mathrm{P} \leq 0.05$; $\mathrm{SEM}-$ standard error of mean; TP - total protein, ALB - albumin, $\mathrm{UA}$ - uric acid, BIL - bilirubin, $\mathrm{n}=10$.

Table 5. Parameters of carbohydrate and lipid metabolism in the blood of chickens receiving fermented soybean meal (FSBM)

\begin{tabular}{l|c|c|c|c|c}
\hline \multicolumn{1}{c|}{ Treatment } & $\begin{array}{c}\text { GLU } \\
(\mathrm{mmol} / \mathrm{L})\end{array}$ & $\begin{array}{c}\text { CREAT } \\
(\mathrm{mmol} / \mathrm{L})\end{array}$ & $\begin{array}{c}\mathrm{TC} \\
(\mathrm{mmol} / \mathrm{L})\end{array}$ & $\begin{array}{c}\text { HDL } \\
(\mathrm{mmol} / \mathrm{L})\end{array}$ & $\begin{array}{c}\text { TG } \\
(\mathrm{mmol} / \mathrm{L})\end{array}$ \\
\hline Control & 13.67 & 15.58 & $3.054 \mathrm{ab}$ & $1.795 \mathrm{~b}$ & 0.560 \\
FSBM $-3 \%$ & 13.29 & 15.14 & $3.297 \mathrm{a}$ & $1.832 \mathrm{a}$ & 0.554 \\
FSBM $-6 \%$ & 13.76 & 15.54 & $2.969 \mathrm{~b}$ & $1.813 \mathrm{a}$ & 0.540 \\
SEM & 0.036 & 0.132 & 0.052 & 0.226 & 0.062 \\
P-value & 0.143 & 0.113 & 0.047 & 0.021 & 0.332 \\
\hline
\end{tabular}

$\mathrm{a}, \mathrm{b}$ - means with different letters within a row are significantly different at $\mathrm{P} \leq 0.05$; $\mathrm{SEM}$ - standard error of mean; GLU - glucose, CREAT - creatinine, TC - total cholesterol, HDL - high-density lipoprotein, TG triacylglycerols, $\mathrm{n}=10$.

Table 6. Enzyme activity in the blood plasma of chickens receiving fermented soybean meal (FSBM)

\begin{tabular}{l|c|c|c|c}
\hline \multicolumn{1}{c}{ Treatment } & $\begin{array}{c}\text { AST } \\
(\mathrm{U} / \mathrm{L})\end{array}$ & $\begin{array}{c}\text { ALT } \\
(\mathrm{U} / \mathrm{L})\end{array}$ & $\begin{array}{c}\text { CK } \\
(\mathrm{U} / \mathrm{L})\end{array}$ & $\begin{array}{c}\text { GGT } \\
(\mathrm{U} / \mathrm{L})\end{array}$ \\
\hline Control & $224.1 \mathrm{~b}$ & 4.596 & 2720.0 & 27.12 \\
FSBM $-3 \%$ & $264.9 \mathrm{a}$ & 4.674 & 2627.2 & 26.09 \\
FSBM $-6 \%$ & $275.0 \mathrm{a}$ & 4.665 & 2828.7 & 26.14 \\
SEM & 0.216 & 0.089 & 0.652 & 0.326 \\
P-value & 0.044 & 0.323 & 0.912 & 0.125 \\
\hline
\end{tabular}

$\mathrm{a}, \mathrm{b}$ - means with different letters within a row are significantly different at $\mathrm{P} \leq 0.05$; SEM - standard error of mean; AST - aspartate aminotransferase, ALT - alanine aminotransferase, CK - creatine kinase, GGT - gammaglutamyl transferase, $\mathrm{n}=10$.

Table 7. Blood redox parameters of chickens receiving fermented soybean meal (FSBM)

\begin{tabular}{l|c|c|c|c|c|c}
\hline \multicolumn{1}{c}{ Treatment } & $\begin{array}{c}\text { LOOH } \\
(\mu \mathrm{mol} / \mathrm{L})\end{array}$ & $\begin{array}{c}\text { MDA } \\
(\mu \mathrm{mol} / \mathrm{L})\end{array}$ & $\begin{array}{c}\text { FRAP } \\
(\mu \mathrm{mol} / \mathrm{L})\end{array}$ & $\begin{array}{c}\text { GSH + GSSG } \\
(\mu \mathrm{mol} / \mathrm{L})\end{array}$ & $\begin{array}{c}\text { SOD } \\
(\mathrm{U} / \mathrm{mL})\end{array}$ & $\begin{array}{c}\text { CAT } \\
(\mathrm{U} / \mathrm{mL})\end{array}$ \\
\hline Control & 17.80 & 1.188 & $103.3 \mathrm{~b}$ & $0.188 \mathrm{~b}$ & 25.15 & 6.896 \\
FSBM $-3 \%$ & 17.00 & 1.174 & $131.9 \mathrm{a}$ & $0.207 \mathrm{a}$ & 25.08 & 6.993 \\
FSBM $-6 \%$ & 17.64 & 1.194 & $139.7 \mathrm{a}$ & $0.208 \mathrm{a}$ & 25.09 & 7.022 \\
SEM & 0.012 & 0.142 & 0.088 & 0.007 & 0.008 & 0.128 \\
P-value & 0.234 & 0.142 & $<0.001$ & 0.021 & 0.209 & 0.083 \\
\hline
\end{tabular}

$\mathrm{a}, \mathrm{b}$ - means with different superscripts within a row are significantly different at $\mathrm{P} \leq 0.05 ; \mathrm{SEM}$ - standard error of mean; $\mathrm{LOOH}$ - lipid hydroperoxides, MDA - malondialdehyde, FRAP - total antioxidant potential, $\mathrm{SOD}$ - superoxide dismutase, CAT - catalase, $\mathrm{n}=10$. 
Table 8. Mineral content in the blood of chickens receiving fermented soybean meal (FSBM)

\begin{tabular}{l|c|c|c}
\hline Treatment & $\begin{array}{c}\mathrm{Zn} \\
(\mu \mathrm{mol} / \mathrm{L})\end{array}$ & $\begin{array}{c}\mathrm{Cu} \\
(\mu \mathrm{mol} / \mathrm{L})\end{array}$ & $\begin{array}{c}\mathrm{Fe} \\
(\mu \mathrm{mol} / \mathrm{L})\end{array}$ \\
\hline Control & $71.21 \mathrm{~b}$ & $2.779 \mathrm{~b}$ & $37.50 \mathrm{a}$ \\
FSBM $-3 \%$ & $98.21 \mathrm{a}$ & $2.886 \mathrm{~b}$ & $35.75 \mathrm{ab}$ \\
FSBM $-6 \%$ & $107.5 \mathrm{a}$ & $3.129 \mathrm{a}$ & $21.50 \mathrm{~b}$ \\
SEM & 0.189 & 0.037 & 0.018 \\
$P$-value & 0.001 & $<0.001$ & $<0.001$ \\
\hline
\end{tabular}

$\mathrm{a}, \mathrm{b}-$ means with different letters within a row are significantly different at $\mathrm{P} \leq 0.05$; SEM - standard error of mean, $\mathrm{n}=10$.

\section{Discussion}

In the present experiment, in comparison to FSB, FSBM contained more $\mathrm{CP}$, LAB, methionine, lysine and, in particular, was characterized by more than 30 -fold higher lactic acid contents. The favourable effects of fermentation include the decrease in the amount of NSP and elimination of anti-nutritional factors, such as TI, B-conglycinin and raffinose (Chachaj et al., 2019 b). Similar effects were also described by other authors (Hong et al., 2004; Teng et al., 2012; Jazi et al., 2018).

Our research has shown that diet with 6\% share of FSBM improved the body weight gain of chickens for a total rearing period. Similarly, Feng et al. (2007 a) and Soumeh et al. (2019) demonstrated beneficial effect of replacing FSM with FSBM on the growth performance of chickens. The experiment conducted by Kim et al. (2016) has revealed that feeding of fermented soybean meal (at the level of 3\%) during early phase influenced positively the subsequent growth performance in broiler chickens. The improved growth performance as a consequence of replacing FSM with FSBM was demonstrated also in experiments on turkeys (Chachaj et al., 2019 b) and quails (Jazi et al., 2018). The factors determining this effect may be an improvement of the nutritional value of FSBM (Feng et al., 2007 a; Yuan et al., 2017) and the elimination of ANFs (Hong et al., 2004). It is worth noting that soybean contains highly allergenic proteins (glycinin, ß-conglycinin, and trypsin inhibitors), the presence of which may induce hypersensitivity reactions and cause damage to the intestinal mucosa, leading to poorer growth performance (Wang et al., 2012). The diets with FSMB containing smaller amounts of allergens as compared to FSM may lead to the improvement of performance parameters. Chachaj et al. (2019 b) have revealed that partial replacement of SBM with FSBM in turkeys diet positively influenced morphology and microbial profile of the gut, and had beneficial effect on the growth performance. Therefore, the growth-promoting activity of FSBM could also be due to the improvement in intestinal morphology and microbiome, which was also observed by other investigators (Jazi et al., 2018, 2019; Mathivanan et al., 2006). Soumeh et al. (2019) demonstrated that chickens diet with FSBM not only positively affects intestinal morphology, stimulates activity of digestive enzymes, but also suppresses skeletal muscle protein degradation and increases an expression 
of hepatic IGF-1. Hepatic IGF-1 is considered as the main anabolic factor stimulating protein muscle synthesis in mammals and poultry (Guobin et al., 2011).

Measurement of blood biochemical parameters enables assessment of the course of metabolism of basic nutrients, organ function, and the general health of animals (Piotrowska et al., 2011). The results of the study show that the dietary inclusion of FSBM (both 3\% and 6\%) in place of SBM significantly increased the level of TP in the blood, while reducing the content of urea, which is one of end products of protein catabolism. A decrease in the amount of blood urea nitrogen in chickens receiving FSBM in their feed has been reported by Feng et al. (2007 a). According to the authors, a reduction in this parameter in the blood indicates effective utilization of nitrogen. Similar observations have also been made in piglets receiving feed with $5 \%, 10 \%$ and $15 \%$ FSBM (Zhu et al., 2017). In addition to a decrease in the amount of urea nitrogen, the authors also noted an increase in TP, ALB, ALP and GLU levels in the blood.

The diet with 3\% and 6\% FSBM also caused an increase in AST activity, but it remained within physiological limits (it did not exceed $275 \mathrm{U} \mathrm{l}^{-1}$ ). An increase in the activity of this enzyme can only be considered significant when it exceeds $800 \mathrm{U}$ $1^{-1}$ (Kalavathy et al., 2003). An elevation in aminotransferases activity (alanine and aspartate) has also been found in turkeys that received 9 and 10\% FSBM in their feed (Chachaj et al., 2019 b). Elevated AST activity may be indicative of functional disorders (degenerative changes) in the liver. However, according to Otto-Ślusarczyk et al. (2016), AST should not be associated only with diagnostics of liver disease, because it is a key enzyme in systemic metabolism involved in processes occurring in many tissues and organs of the body. It should be noted that no post-mortem lesions were observed in the liver or other organs, whose macroscopic appearance in chickens fed FSBM was normal. The elevation in AST activity in these birds was rather due to an increase in the rate of amino acid transformation, especially taking into account the values of other parameters of protein metabolism (the increase in TP and the decrease in UREA contents). In plasma of birds fed diet with FSBM a decrease in BIL content was observed, but it is no pathological phenomenon in contrast to hyperbilirubinemia (Fevery, 2008) .

The activity of ALT, CK and GGT as well the GLU and CREAT levels in blood of birds receiving FSBM remained unchanged, but changes in lipid metabolism indices were observed. Both the $3 \%$ and $6 \%$ share of FSBM caused an increase in HDL cholesterol, and there was also a slight decrease in TC in the blood of chickens fed $6 \%$ FSBM. Modification of blood lipid parameters as a result of using fermented feeds in poultry diets has been observed in quails (Jazi et al., 2018), geese (Chen et al., 2013) and piglets (Hung et al., 2008). A similar effect has also been reported in birds given a probiotic (Seifi et al., 2017; Kalavathy et al., 2003). Lactic acid bacteria are known to have the ability to lower TC and TG by increasing the excretion of bile acids in the faeces (Liong and Shah, 2005) and inhibiting 3-hydroxy-3-methylglutaryl-CoAreductase, a key enzyme in cholesterol synthesis (Seifi et al., 2017). The observed increase in HDL cholesterol in the blood plasma of chickens receiving FSBM may be the effect of stimulation of the antioxidant system and thus suppression of lipid oxidation processes. The results of the analysis of redox parameters in 
chickens receiving FSBM indicate that this diet caused a significant increase in the total antioxidant potential of the plasma (FRAP) and in glutathione, but did not affect the activity of antioxidant enzymes. According to Wongputtisin et al. (2007), fermentation of soybean increases its antioxidant activity through various mechanisms. One of these involves the release of lipophilic aglycones of the isoflavone glycosides daidzein and genistein (due to the action of microbial glucosidases), which are more effective scavengers of free radicals than the corresponding glycosides (Lin et al., 2006). Another mechanism explaining the increase in the antioxidant potential of soybean through its fermentation is the increase in free amino acids, especially tyrosine, methionine, histidine, tryptophan and lysine, which are treated as antioxidants (Wang and Mejia, 2005). Some researchers also point out that during fermentation the activity of microbial proteases modifies soy proteins in a manner that leads to exposure of the more active $\mathrm{R}$ groups of amino acids. Thus, peptides present in fermented soybean display greater antioxidant activity than the native protein (Wang and Mejia, 2005). A study by Drażbo et al. (2018) in which fermented rapeseed cake was used in the diet of turkeys showed an increase in FRAP and GSH+GSSG in the plasma, as well as a reduction in LOOH and MDA levels. Fermentation also increases the availability of minerals from seeds, which are found there in bound form as phytate or oxalate. Owing to the action of microbial enzymes, micronutrients (Fe, $\mathrm{Zn}$ and $\mathrm{Cu}$ ) and macronutrients $(\mathrm{Ca}, \mathrm{Mg}, \mathrm{Mn}$ and $\mathrm{P})$ are released from these complexes, which increases their bioavailability (Bering et al., 2006). This phenomenon is probably responsible for the increase in the level of zinc in the blood of chickens receiving FSBM (both $3 \%$ and $6 \%$ ) and copper ( $6 \%$ FSBM). In this context it is difficult to explain the decrease in the level of iron in these chickens, especially since not only is this element released from phytate, but during fermentation $\mathrm{Fe}^{2+}$ is converted to the more easily absorbed form of $\mathrm{Fe}^{3+}$. Therefore, the reverse relationship, i.e. an increase in the amount of this metal in the blood of the experimental chickens, would be expected.

\section{Conclusions}

Summing up, the results of the experiment indicate that the inclusion of $3 \%$ or $6 \%$ share of FSBM in the diet of chickens stimulated antioxidant defence mechanisms, which was manifested by an increase in FRAP and plasma total glutathione levels. The diet containing FSBM also increased in HDL cholesterol content and positively influenced protein metabolism. In the blood of chickens receiving FSBM an increase in TP content, AST activity and a decrease in UREA level were noted, which may indicate a better utilization of nitrogen from feed. Moreover, feeding chickens with $6 \%$ FSBM caused an improvement in body weight gain. Therefore, dietary inclusion of $6 \%$ share of FSBM in place of SBM seems to be more favourable than $3 \%$ share.

\section{Acknowledgements}

This research was partially supported by FeedStar Ltd., Poland and European Protein, Denmark. Work financed from ZKT/ZIR. 


\section{References}

A shayerizadeh A., Dastar B., Shams M., Shargh A.R., Mahoonak S., Zerehdaran S. (2017). Fermented rapeseed meal is effective in controlling Salmonella enterica serovar Typhimurium infection and improving growth performance in broiler chicks. Vet. Microbiol., 201: 93-102.

Bering S., Suchdev S., Sjøltov L., Berggren A., Tetens I., Bukhave K. (2006). A lactic acid-fermented oat gruel increases non-haem iron absorption from a phytate-rich meal in healthy women of childbearing age. Br. J. Nutr., 96: 80-85.

Chachaj R., Sembratowicz I., Krauze M., Ognik K. (2019 a). The effect of fermented soybean meal in chicken feed on performance and immune status. J. Anim. Feed Sci., 28: 263-271.

Cha chaj R., S e mbrat ow i c z I., Krauze M., S tę pniow s ka A., Ru sinek - Prystupa E., Czech A., Matusevičius P., Ognik K. (2019 b). The effect of fermented soybean meal on performance, and biochemical and immunological blood parameters in turkey. Ann. Anim. Sci., 19: 1035-1049.

Cha mpagne C.P., Tompkins T.A., B u ckley N.D., Green-Johnson J.M. (2010). Effect of fermentation by pure and mixed cultures of Streptococcus thermophilus and Lactobacillus helveticus on isoflavone and B-vitamin content of a fermented soy beverage. Food Microbiol., 27: $968-972$.

Chat terje e C., G le d d i e S., X i a o C.W. (2018). Soybean bioactive peptides and their functional properties. Nutrients, 10: 8-11.

Chen W., Zhu X.Z., Wang J.P., Wang Z.X., Huang Y.Q. (2013). Effects of Bacillus subtilis var. natto and Saccharomyces cerevisiae fermented liquid feed on growth performance, relative organ weight, intestinal microflora, and organ antioxidant status in Landes geese. J. Anim. Sci., 91: 978-985.

Cho i J., Rahman Md M., L e e S.Y., Chang K.H., L e e S.M. (2016). Effects of dietary inclusion of fermented soybean meal with Phaffia rhodozyma on growth, muscle pigmentation, and antioxidant activity of juvenile rainbow trout (Oncorhynchus mykiss). Turk. J. Fish. Aq. Sci., 16: 91-101.

Drażbo A., Ognik K., Z aw orska A., F erenc K., J a n k ow s ki J. (2018). The effect of raw and fermented rapeseed cake on the metabolic parameters, immune status, and intestinal morphology of turkeys. Poultry Sci., 97: 3910-3920.

Drażbo A., K ozłow ski K., Ognik K., Z aw orska A., Jankow s ki J. (2019). The effect of raw and fermented rapeseed cake on growth performance, carcass traits and breast meat quality in turkey. Poultry Sci., 98: 6161-6169.

Engberg R.M., Hammershoj M., Johansen N.F., Abous ek ken M.S, S te enfeldt S., J e n s e n B. (2009). Fermented feed for laying hens: Effects on egg production, egg quality, plumage condition and composition and activity of the intestinal microflora. Brit. Poult. Sci., 50: 228-239.

F e n g J., Li u Z.R., X u Y., Li u Y., L u Y.P. (2007 a). Effects of Aspergillus oryzae 3.042 fermented soybean meal on growth performance and plasma biochemical parameters in broilers. Anim. Feed Sci. Technol., 134: 235-242.

F eng J., Liu X., Xu Z.R,. Wang Y.Z, Li u J.X. (2007 b). Effects of fermented soybean meal on digestive enzyme activities and intestinal morphology in broilers. Poultry Sci., 86: 1149-1154.

F e ver y J. (2008). Bilirubin in clinical practice: a review. Liver Int., 25: 592-605.

Frias J., Song Y.S., Martínez-Villaluenga C., De Mejia E.G., Vidal-Valved e C. (2008). Immunoreactivity and amino acid content of fermented soybean products. J. Agric. Food Chem., 56: 99-105.

Gu obin C., Xiang ping L., Jing L. (2011). Temporal and spatial expression of the pax-7 gene during chicken embryo and postnatal development. J. Anim. Vet. Adv., 10: 1785-1788.

Hirabayashi M., Matsui T., Yano H. (1998). Fermentation of soybean flour with Aspergillus usamii improves availabilities of zinc and iron in rats. J. Nutr. Sci. Vitaminol. (Tokyo), 44: $877-886$.

Hong K.J., L e e C.H., K i m S.W. (2004). Aspergillus oryzae GB-107 fermentation improves nutritional quality of food soybeans and soybean meal. J. Med. Food, 7: 430-435.

H ubert J., B erger M., N e p ve u F., P a u 1 F., D a y d e J. (2008). Effects of fermentation on the phytochemical composition and antioxidant properties of soy germ. Food Chem., 109: 709-721. 
Hung A., Su T., Lis o C. (2008). Effect of probiotic combination fermented soybean meal on growth performance lipid metabolism and immunological response of growing finishing pigs. Asian J. Anim. Vet. Adv., 3: 421-436.

Jazi V., Ashayerizadeh A., Toghyani M., Shabani A., Tellez G., Toghyani M. (2018). Fermented soybean meal exhibits probiotic properties when included in Japanese quail diet in replacement of soybean meal. Poultry Sci., 97: 2113-2122.

Jazi V., Mohebodini H., Ashayerizadeh A., Shabani A., Barekatain R. (2019). Fermented soybean meal ameliorates Salmonella typhimurium infection in young broiler chickens. Poultry Sci., 98: 5648-5660.

K a lava thy R., A b d u 11 a h N., J a l a l u d in S., H o Y.W. (2003). Effects of Lactobacillus cultures on growth performance, abdominal fat deposition, serum lipids and weight of organs of broiler chickens. Brit. Poult. Sci., 44: 139-144.

K i m S.K., K i m T.H., L e e S.K., Ch ang K.H., Ch o S.J., L e e K.W., A n B.K. (2016). The use of fermented soybean meals during early phase affects subsequent growth and physiological response in broiler chicks. Asian-Australas. J. Anim. Sci., 29: 1287-1293.

L in C.H., We i Y.T., Chou C.C. (2006). Enhanced antioxidative activity of soybean koji prepared with various filamentous fungi. Food Microbiol., 23: 628-633.

Li ong M.T., Shah N.P. (2005). Bile salt deconjugation and BSH activity of five bifidobacterial strains and their cholesterol co-precipitating properties. Food Res. Int., 38: 135-142.

Luo Z., Yu S., Zhu Y., Zhang J., Xu W., X u J. (2018). Effect of various levels of isoflavone aglycone-enriched fermented soybean meal on redox status, serum hormones and milk quality in ewes. South J. Anim. Sci., 48: 673-682.

Mah J.H., P ark Y.K., J in Y.H., L e e J.H., Hw ang H.J. (2019). Bacterial production and control of biogenic amines in Asian fermented soybean foods. Foods, 8: 85; doi: 10.3390/foods8020085.

Ma k o w s k a - W ą ś J., J a n e c z k o Z. (2004). Bioavailability of plant polyphenols (in Polish). Post. Fitoter., 3: 126-137.

Mathivanan R., S e lvaraj P., N a nja p pan K. (2006). Feeding of fermented soybean meal on broiler performance. Int. J. Poult. Sci., 5: 868-872.

Mukherjee R., Chakraborty R., Abhishek D. (2016). Role of fermentation in improving nutritional quality of soybean meal - a review. Asian-Australas. J. Anim. Sci., 29: 1523-1529.

O g n i k K., We r te le c k i T. (2012). Effect of different vitamin E sources and levels on selected oxidative status indices in blood and tissues as well as on rearing performance of slaughter turkey hens. J. Appl. Poult. Res., 21: 259-271.

O t to - Ślus arczyk D., Graboń W., Mi elc zarek-Put a M. (2016). Aspartate aminotransferase - key enzyme in the human systemic metabolism. Post. Hig. Med. Dośw., 70: 219-230.

Piotrowska A., Burlikowska K., Szy meczko R. (2011). Changes in blood chemistry in broiler chickens during the fattening period. Folia Biol., 59: 183-187.

Seifi K., Karimi Torshizi M.A., Rahimi S., Kazemifard M. (2017). Efficiency of early, single-dose probiotic administration methods on performance, small intestinal morphology, blood biochemistry, and immune response of Japanese quail. Poultry Sci., 96: 2151-2158.

S m u lik ow s k a S., R u t k ow s ki A. (2005). Nutrient requirements of poultry. Feeding recommendations and nutritive value of feed (in Polish). 4th ed. The Kielanowski Institute of Animal Physiology and Nutrition of the Polish Academy of Sciences, Jabłonna by Warszawa.

Soumeh E.A., Mohebodini H., Toghyani M., Shabani A., Ashayerizadeh A., Jaz i V. (2019). Synergistic effects of fermented soybean meal and mannan-oligosaccharide on growth performance, digestive functions, and hepatic gene expression in broiler chickens. Poultry Sci., 98 : 6797-6807.

S u g i h a r t o S., R a n j it k a r S. (2019). Recent advances in fermented feeds towards improved broiler chicken performance, gastrointestinal tract microecology and immune responses: A review. Anim. Nutr., 5: 1-10.

Teng D., G a o M., Yang Y., Li u B., Ti a n Z., Wang J. (2012). Biomodification of soybean meal with Bacillus subtilis or Aspergillus oryzae. Biocatal. Agric. Biotechnol., 1: 32-38.

Wang W., de Mejia G.E. (2005). A new frontier in soy bioactive peptides that may prevent agerelated diseases. Compr. Rev. Food Sci. Food Saf., 4: 63-78. 
Wan g L.C., We n C., J i a n g Z.Y., Z h o u Y.M. (2012). Evaluation of the partial replacement of highprotein feedstuff with fermented soybean meal in broiler diets. J. Appl. Poult. Res., 21: 849-855.

Wongputtis in P., Khan ong nuch C., Pong pi a chan P., L u m y ong S. (2007). Antioxidant activity improvement of soybean meal by microbial fermentation. Res. J. Microbiol., 2: 577-583.

Yuan L., Chang J., Y in Q., Lu M., Di Y., Wang P., Wang Z., Wang E., Lu F. (2017). Fermented soybean meal improves the growth performance, nutrient digestibility, and microbial flora in piglets. Anim. Nutr., 3: 19-24.

Zhu J., Ga o M., Zhang R., S un Z., Wang C., Yang F., Huang T., Qu S., Zhao L., Li Y., H a o Z. (2017). Effects of soybean meal fermented by L. plantarum, B. subtilis and S. cerevisieae on growth, immune function and intestinal morphology in weaned piglets. Microb. Cell Fact., 16: 191.

Received: 9 X 2019

Accepted: 8 I 2020 